\title{
Chronic Exposure of HIT Cells to High Glucose Concentrations Paradoxically Decreases Insulin Gene Transcription and Alters Binding of Insulin Gene Regulatory Protein
}

\author{
L. Karl Olson, * J. Bruce Redmon, * Howard C. Towle, ${ }^{*}$ and R. Paul Robertson * \\ ${ }^{*}$ Diabetes Center and the Division of Endocrinology and Metabolism, Department of Medicine, and ${ }^{\ddagger}$ Department of Biochemistry and \\ Institute of Human Genetics, University of Minnesota Medical School, Minneapolis, Minnesota 55455
}

\begin{abstract}
Chronically culturing HIT-T15 cells in media containing high glucose concentrations leads to decreased insulin mRNA levels, insulin content, and insulin secretion. These changes can be prevented by culturing the cells in media containing lower glucose levels (Robertson, R. P., H.-J. Zhang, K. L. Pyzdrowski, and T. F. Walseth. 1992. J. Clin. Invest. 90:320-325). The mechanism of this seemingly paradoxical phenomenon was examined by transiently transfecting HIT cells with a chloramphenicol acetyl transferase (CAT) reporter gene controlled by the 5'-regulatory domain of the human insulin gene (INSCAT). Early passages of HIT cells readily expressed INSCAT, whereas late passages of cells chronically cultured in $11.1 \mathrm{mM}$ glucose expressed only $28.7 \pm 2.3 \%$ (mean \pm SEM) of the CAT activity expressed in early passages. In contrast, late passages of HIT cells chronically cultured in $0.8 \mathrm{mM}$ glucose retained the ability to express the INSCAT reporter gene to $69.6 \pm 10.0 \%$ of the CAT activity observed in early passages. The decrease in INSCAT expression in late passages of cells serially cultured in $11.1 \mathrm{mM}$ glucose was associated with the inability to form a specific nuclear protein-DNA complex with the CT motifs of the human insulin promoter. Formation of this specific protein-DNA complex was preserved in late passages of HIT cells when serially cultured in $0.8 \mathrm{mM}$ glucose. Mutations of the CT motifs caused markedly diminished CAT activity in all passages examined. These data indicate that chronic exposure of the $\beta$ cell to high glucose concentrations can paradoxically decrease insulin gene transcription, in part, by altering the ability of a regulatory protein (GSTF) to interact with the insulin gene promoter. This provides a potential mechanism for glucotoxic effects on the $\beta$ cell at the level of the insulin gene. (J. Clin. Invest. 1993. 92:514-519.) Key words: glucose toxicity $\bullet$ diabetes mellitus $\bullet$ transcription factor
\end{abstract}

\section{Introduction}

Chronic hyperglycemia in humans with type II diabetes mellitus may contribute secondarily to defective glucose-induced

Address reprint requests to L. Karl Olson, Ph.D., The Diabetes Center, Box 101 UMHC, University of Minnesota, Minneapolis, MN 55455. Received for publication 12 November 1992 and in revised form 11 March 1993.

J. Clin. Invest.

(c) The American Society for Clinical Investigation, Inc. 0021-9738/93/07/0514/06 \$2.00

Volume 92, July 1993, 514-519 insulin secretion, the so-called glucose toxicity theory (reviewed in references 1 and 2). Normalization of blood glucose levels of type II diabetic patients partially restores defective insulin release (3-7), and normalization of glucose levels in several hyperglycemic animal models leads to full restoration of normal insulin secretion (8-10). However, no biochemical mechanism has been identified for glucotoxic effects on the pancreatic $\beta$ cell (2). Our previous observations (11) suggested that one potential explanation could involve an alteration in insulin gene expression.

The HIT-T 15 cell is a clonal pancreatic $\beta$ cell line derived from SV-40 transfected Syrian hamster pancreatic islets (12). This cell line synthesizes and releases insulin in response to physiological secretagogues including glucose (13-18). However, the HIT cell loses its ability to secrete insulin with increasing passage $(12,14,18)$. Recently, Robertson et al. have shown that the loss of insulin secretion is associated with decreased insulin content and insulin mRNA, and that this loss can be prevented by passaging HIT cells in low glucose $(0.8$ $\mathrm{mM}$ ) rather than the high glucose $(11.1 \mathrm{mM})$ concentrations usually used when culturing these cells (11). The studies reported here were designed to determine whether a seemingly paradoxical decrease in insulin gene transcription might be a mechanism through which chronically culturing HIT cells in high glucose concentrations decreases insulin content and insulin mRNA.

We sought to answer three questions: ( $a$ ) Does serially passaging HIT cells in high glucose concentrations lead to decreased insulin gene transcription? $(b)$ Does serially passaging HIT cells in a low glucose concentration preserve insulin gene transcription? (c) Is there evidence for altered activity of insulin gene transcription factors that might explain the observed changes in insulin gene transcription?

\section{Methods}

HIT cell cultures. HIT cell stocks were routinely grown at $5 \% \mathrm{CO}_{2} /$ $95 \%$ air at $37^{\circ} \mathrm{C}$ in RPMI- 1640 media containing $10 \%$ FBS and 11.1 $\mathrm{mM}$ glucose, and passaged weekly after trypsin-EDTA detachment (18). Beginning at passage 70, HIT cells were split weekly and continuously cultured in RPMI-1640 containing either 11.1 or $0.8 \mathrm{mM}$ glucose through passage 140 (11). These concentrations were chosen because they stimulate insulin release at either extreme of the HIT cell insulin response curve (18).

Plasmid constructs and oligodeoxynucleotides. The following oligodeoxynucleotides were synthesized by the Microchemical Facility, Institute of Human Genetics, University of Minnesota. 


\author{
$\operatorname{Ins}(-326 /-307)$ \\ Ins $(+11 /+30)$ \\ $\operatorname{Ins}(-230 /-201)$ \\ InsmCT2 $(-230 /-201) \mathrm{a}$ \\ InsmCT2 $(-230 /-201) \mathrm{b}$ \\ Ins $(-249 /-220)$ \\ $\operatorname{Ins}(-94 /-65)$ \\ InsmCT $1(-94 /-65)$ a \\ InsmCT1 $1(-94 /-65) \mathrm{b}$
}

\author{
5'-GCGTCTAGATCTCCTGGTCTAATGTGGAA-3' \\ 5'-GCGCTCGAGCTCTTCTGATGCAGCCTGTC-3' \\ 5'-GCGTCTAGACCCCTGGTTAAGACTCTAATGACCCGCTGG-3' \\ 3'-GGGGACCAATTCTGAGATTACTGGGCGACC-5' \\ 5'-CCCCTGGTTAAGACTACGCGTACCCGCTGGTCC-3' \\ 3'-GGGGACCAATTCTGATGCGCATGGGCGACCAGG-5' \\ 5'-GCGTCTAGAGACAGGTCTGGCCACCGGGCCCCTGGTTAA-3' \\ 3'-CTGTCCAGACCGGTGGCCCGGGGACCAATT-5' \\ 5'-CCACCCCAGGCCCTAATGGGCCAG-3' \\ 3'-GGTGGGGTCCGGGATTACCCGGTCCGCCGT-5' \\ 5'-CCACCCCAGGCCGCGCGCGGCCAGGCGGCA-3' \\ 3'-GGTGGGGTCCGGCGCGCGCCGGTCCGCCGT-5'
}

The plasmid INSCAT, containing the human insulin gene sequences -326 to +30 , was constructed as follows. The sequences from -326 to +30 were amplified by PCR using oligodeoxynucleotides Ins $(-326 /-307)$ and $\operatorname{Ins}(+11 /+30)$ as primers and phins 300 plasmid containing the human insulin gene (a gift from Dr. Graeme I. Bell, Howard Hughes Medical Institute and the University of Chicago) as a template. Xbal and Xhol sites were present on the 5'- and 3'-ends of the primers used for PCR, respectively. This DNA fragment was cleaved with $\mathrm{Xbal}$ and $\mathrm{Xhol}$ and then subcloned into the $\mathrm{Xbal}$ and $\mathrm{Xhol}$ sites of $\mathrm{pCAT}(\mathrm{An})$, a promoterless plasmid containing the bacterial chloramphenicol acetyl transferase $(\text { CAT })^{1}$ gene (19).

Plasmids containing mutations in the CT motifs of the insulin promoter region were constructed by a PCR-based mutagenesis technique. The mCT2CAT plasmid was constructed by PCR amplification of sequences -326 to -201 and sequences -230 to +30 using oligodeoxynucleotides Ins $(-326 /-307)$ and InsmCT2 $(-230 /-201) \mathrm{b}$ and using Ins $(+11 /+30)$ and InsmCT $2(-230 /-201)$ a as primers, respectively, and INSCAT as the template. The InsmCT2 $(-230 /-201)$ oligodeoxynucleotide has a MluI site, replacing the native insulin gene sequences at $-215 /-210$. The -326 to -201 PCR product was then cleaved with $\mathrm{XbaI}$ and MluI, while the -230 to $+30 \mathrm{PCR}$ product was cleaved with $\mathrm{XhoI}$ and MluI. These PCR products were then simultaneously subcloned into the XbaI and XhoI sites of pCAT(An). The mCT1CAT plasmid was constructed by PCR amplification of sequences -326 to -65 and sequences -94 to +30 using oligodeoxynucleotides Ins $(-326 /-307)$ and InsmCT1 $(-94 /-65) \mathrm{b}$ and using Ins $(+11 /$ $+30)$ and InsmCT1 $(-94 /-65)$ a as primers, respectively, and INSCAT as the template. The InsmCT1 $(-94 /-65)$ oligodeoxynucleotide has a BssHII site replacing the native insulin gene sequences at -82 / -77 . The -326 to -65 PCR product was then cleaved with Xbal and BssHII, while the -94 to +30 PCR product was cleaved with XhoI and BssHII. These PCR products were then subcloned into the $\mathrm{XbaI}$ and Xhol sites of pCAT(An). The mCT1CT2CAT plasmid was constructed by the same method as for the mCT1CAT plasmid except that the mCT2CAT plasmid was used as the DNA template during PCR. Proper insertion and confirmation of sequence for all vectors were determined by dideoxy sequencing.

Cell transfections and CAT assay. HIT cells were subcultured in RPMI- 1640 containing $11.1 \mathrm{mM}$ glucose at a density of $1.2 \times 10^{6}$ cells per well in 6-well plates (diameter $3.5 \mathrm{~cm}$ ) $2 \mathrm{~d}$ before each study. Duplicate wells of cells were then transfected with 0.5 to $1.0 \mu \mathrm{g}$ of INSCAT DNA or 0.1 to $0.5 \mu \mathrm{g}$ of RSVCAT DNA by a liposome-mediated method (Lipofectin; BRL, Gaithersburg, MD). All transfections and subsequent incubations were done in $11.1 \mathrm{mM}$ glucose. Cells were rinsed with FBS-free RPMI-1640, then $1 \mathrm{ml}$ of FBS-free RPMI-1640 containing 1:4 (wt:wt) plasmid DNA to lipofectin was added and cells were incubated for $5 \mathrm{~h}$ at $37^{\circ} \mathrm{C}$, after which $2 \mathrm{ml} \mathrm{RPMI-} 1640$ containing $15 \%$ FBS was added. $30 \mathrm{~h}$ after transfection, cells were harvested and CAT activity was assayed (20). Data are expressed as relative INS-

1. Abbreviations used in this paper: CAT, chloramphenicol acetyl transferase; EMSA, electrophoretic shift assay; GSTF, glucose-sensitive transcription factor.
CAT to RSVCAT expression to control for variability in transfection efficiency observed between cells cultured in low and high glucose concentrations.

Nuclear extracts and electrophoretic mobility shift assay (EMSA). Nuclear extracts were made from various HIT cell passages according to methods originally described by Dignam et al. (21) and modified by Abmayr and Workman (22). Oligodeoxynucleotides Ins(-230/ $-201)$, Ins $(-249 /-220)$, and Ins $(-94 /-65)$ were annealed and then labeled with $\left[{ }^{32} \mathrm{P}\right] \mathrm{dCTP}$ by filling overhanging 5 '-ends with the large fragment of DNA polymerase 1 . Binding reactions and electrophoresis were performed as described by Shih and Towle (23) except that $0.3 \mu \mathrm{g}$ of poly ( $\mathrm{dI}-\mathrm{dC})$ and poly (dA-dT) were used as nonspecific competitors in the binding reactions.

\section{Results}

Insulin gene promoter activity in HIT cells serially passaged in either $11.1 \mathrm{mM}$ or $0.8 \mathrm{mM}$ glucose. Insulin gene promoter activity in early and late passages of HIT cells chronically cultured in $11.1 \mathrm{mM}$ or $0.8 \mathrm{mM}$ glucose was assessed by transiently transfecting the cells with a CAT reporter gene controlled by the 5'-regulatory domain $(-326$ to +30$)$ of the human insulin gene. HIT cells from passage 73 to 76 cultured in $11.1 \mathrm{mM}$ glucose readily expressed CAT activity when transiently transfected with either INSCAT or RSVCAT (Table I). In early passages of HIT cells the relative expression of INSCAT to RSVCAT was $1.02 \pm 0.02$. The relative expression of INSCAT to RSVCAT was $0.29 \pm 0.02$ for late passages of HIT cells cultured in $11.1 \mathrm{mM}$ glucose. The decrease in relative CAT activity observed in the late passages of HIT cells cultured in 11.1 $\mathrm{mM}$ glucose appears to be specific for INSCAT expression, since RSVCAT expression was the same for both early and late passages of HIT cells ( Table I).

Compared with late passages of HIT cells chronically cultured in $11.1 \mathrm{mM}$ glucose, cells chronically cultured in $0.8 \mathrm{mM}$ glucose expressed 2.4-fold $(P<0.005, n=5)$ more relative CAT activity when transfected with INSCAT (Table I). In late passages of HIT cells serially passaged in $0.8 \mathrm{mM}$ glucose, insulin promoter activity was shown to be $69.6 \pm 10.0 \%$ compared with early passages of cells (Table I). When early and late passages of HIT cells chronically cultured in either $11.1 \mathrm{mM}$ or 0.8 $\mathrm{mM}$ glucose were cotransfected with both INSCAT and a RSVdriven luciferase reporter construct, to control for transfection efficiency, qualitatively similar results to those described in Table I were observed (data not shown). These data suggest that late passages of HIT cells chronically cultured in $0.8 \mathrm{mM}$ glucose have preserved insulin promoter activity, which may explain the preservation of both insulin mRNA and insulin content (11). 
Table I. Expression of INSCAT and RSVCAT in Early Passages and Late Passages of HIT Cells Serially Passaged in Either $11.1 \mathrm{mM}$ or $0.8 \mathrm{mM}$ Glucose

\begin{tabular}{|c|c|c|c|c|c|c|c|c|c|}
\hline \multirow[b]{3}{*}{ Experiment } & \multicolumn{3}{|c|}{ P70 $11.1 \mathrm{mM}$ glucose } & \multicolumn{3}{|c|}{ P130 11.1 mM glucose } & \multicolumn{3}{|c|}{ P130 0.8 mM glucose } \\
\hline & \multicolumn{2}{|c|}{ Percent conversion } & \multirow{2}{*}{$\begin{array}{l}\text { INSCAT: } \\
\text { RSVCAT }\end{array}$} & \multicolumn{2}{|c|}{ Percent conversion } & \multirow{2}{*}{$\begin{array}{l}\text { INSCAT: } \\
\text { RSVCAT }\end{array}$} & \multicolumn{2}{|c|}{ Percent conversion } & \multirow{2}{*}{$\begin{array}{l}\text { INSCAT: } \\
\text { RSVCAT }\end{array}$} \\
\hline & INSCAT & RSVCAT & & INSCAT & RSVCAT & & INSCAT & RSVCAT & \\
\hline 1 & 5.2 & 5.3 & 0.98 & 1.5 & 4.0 & 0.38 & 13.7 & 25.8 & 0.53 \\
\hline 2 & 5.3 & 5.0 & 1.06 & 0.8 & 2.9 & 0.28 & 10.8 & 17.0 & 0.64 \\
\hline 3 & 5.8 & 5.6 & 1.04 & 1.1 & 3.9 & 0.28 & 17.7 & 16.5 & 1.07 \\
\hline 4 & 4.9 & 4.6 & 1.05 & 1.5 & 5.1 & 0.30 & 12.0 & 15.4 & 0.76 \\
\hline 5 & 4.4 & 4.5 & 0.96 & 1.4 & 6.1 & 0.23 & 11.0 & 20.9 & 0.53 \\
\hline Mean \pm SE & $5.1 \pm 0.2$ & $5.0 \pm 0.2$ & $1.02 \pm 0.02$ & $1.3 \pm 0.1$ & $4.4 \pm 0.6$ & $0.29 \pm 0.02^{*}$ & $13.0 \pm 1.3$ & $19.1 \pm 1.9$ & $0.69 \pm 0.10^{\S}$ \\
\hline
\end{tabular}

Percent conversion represents the mean of duplicate transfections for each HIT cell passage. ${ }^{*} P<0.001$, significance of relative INSCAT to RSVCAT expression between early and late passages of HIT cells serially passaged in $11.1 \mathrm{mM}$ glucose. ${ }^{8} P<0.005$, significance of relative INSCAT to RSVCAT expression between late passages of HIT cells serially passaged in either $11.1 \mathrm{mM}$ or $0.8 \mathrm{mM}$ glucose.

Alteration in insulin gene 5'-regulatory domain binding proteins in HIT cells serially cultured in $11.1 \mathrm{mM}$ or $0.8 \mathrm{mM}$ glucose. To determine whether decreased insulin promoter activity might be associated with altered activity of transcription factors that interact with insulin gene regulatory sequences, nuclear extracts were prepared from early passages ( 74 and 80 ) and late passages ( 119 and 133) of HIT cells cultured either in $11.1 \mathrm{mM}$ or $0.8 \mathrm{mM}$ glucose. EMSAs were then performed with two overlapping sequences, $-249 /-220$ and $-230 /$ -201 , of the human insulin promoter. The human insulin promoter sequence $-249 /-220$ contains a strong positive regulatory element (24), while sequences $-230 /-201$ have been shown to bind the $\beta$ cell specific transcription factor, IUF-1 (25).

With an oligodeoxynucleotide probe containing sequences $-230 /-201$ of the human insulin gene, at least 5 DNA-protein complexes were detected when using nuclear extracts from early passages of cells (Fig. $1 A$, lane 2 ). Of these, one prominent DNA-protein complex was absent in nuclear extracts from late passages of HiT cells cultured in $11.1 \mathrm{mM}$ glucose (Fig. 1 $A$, lane 3 ). In contrast, nuclear extracts made from later passages of cells serially passaged in $0.8 \mathrm{mM}$ glucose retained the ability to form this DNA-protein complex (Fig. $1 \mathrm{~A}$, lane 4). The specificity of the DNA-protein complexes formed with the different extracts was determined by use of an excess of unlabeled DNA from $-230 /-201$ to compete for binding (Fig. $1 A$, lanes 5-7). This slow mobility complex, present in early passages and late passages of cells cultured in $0.8 \mathrm{mM}$ glucose and absent in late passages of cells cultured in $11.1 \mathrm{mM}$ glucose, is designated as the glucose-sensitive transcription factor (GSTF). To validate that the loss of a specific DNA binding protein in nuclear extracts from HIT cells serially passaged in $0.8 \mathrm{mM}$ glucose was not due to an aberration of the nuclear extraction, we tested the various preparations for activity of the ubiquitous MLTF nuclear factor. All the HIT cell nuclear extractions shifted an MLTF DNA probe to the same extent (data not shown), suggesting that all the nuclear preparations were active. Furthermore, several other nuclear factors binding to the $-230 /-201$ fragment were also unchanged in the different preparations (Fig. $1 A$ ).

The oligodeoxynucleotide probe containing the sequences $-249 /-220$ of the human insulin gene was used to search for changes in other DNA binding proteins from HIT cells passaged either in $11.1 \mathrm{mM}$ or $0.8 \mathrm{mM}$ glucose. Nuclear extracts from early and late passages of HIT cells serially passaged in 11.1 or $0.8 \mathrm{mM}$ glucose shifted this oligodeoxynucleotide to the same extent (Fig. $1 B$ ). These data demonstrate that the differences in INSCAT expression in the early and late passages of HIT cells serially passaged in either $11.1 \mathrm{mM}$ or $0.8 \mathrm{mM}$
A. $-230 /-201$

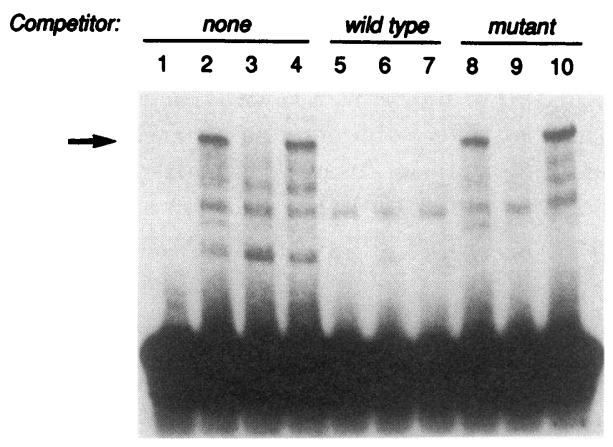

B. $-249 /-220$

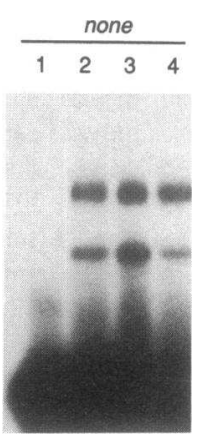

Figure 1. Analysis of protein binding to the insulin promoter sequences from -230 to -201 and -249 to -220 using nuclear extracts from an early passage and late passages of HIT cells serially passaged in either $11.1 \mathrm{mM}$ or $0.8 \mathrm{mM}$ glucose. $(A)$ EMSA using ${ }^{32} \mathrm{P}$-labeled insulin promoter sequence -230 to -201 . Lane 1, free probe; lanes 2,5,8, nuclear extract from HIT cell passage 74; lanes 3,6,9, nuclear extract from HIT cell passage 133 serially passaged in $11.1 \mathrm{mM}$ glucose; lanes 4,7,10, nuclear extracts from HIT cells passage 133 serially passaged in $0.8 \mathrm{mM}$ glucose. Competitor added, lanes 5-7, 100-fold molar excess of unlabeled wild type sequence -230 to -201 ; lanes 8-10, 100-fold molar excess of unlabeled mutated -230 to -201 . Arrow indicates DNA-protein complex present in early passages of HIT cells and late passages of HIT cells cultured in $0.8 \mathrm{mM}$ glucose, but not in late passages of HIT cells cultured in $11.1 \mathrm{mM}$ glucose. $(B)$ EMSA using ${ }^{32} \mathrm{P}$-labeled insulin promoter sequence -249 to -220 . Lane 1, free probe; lanes $2-4$, nuclear extracts from HIT cell passage 74 and passage 133 serially passaged in $11.1 \mathrm{mM}$ glucose and $0.8 \mathrm{mM}$ glucose, respectively. This figure represents results observed for two independent nuclear extractions from each HIT cell passage described. These data also represent a minimum of three independent experiments per condition $(n=3)$. 
glucose are not due to changes in the binding of nuclear factors to this strong enhancer element.

The CT2 motif (CTAATG) located at $-215 /-210$ of the human insulin promoter has previously been shown to be the binding site for a transcription factor, IUF-1 (25). To test whether this sequence might be a site for binding of GSTF, the sequence CTAATG was mutated to ACGCGT in the -230 / -201 oligodeoxynucleotide. This mutated oligodeoxynucleotide no longer competed for the specific DNA-protein complex that was only present in the early passages cells and late passages of HIT cells serially passaged in $0.8 \mathrm{mM}$ glucose (Fig. $1 A$, lanes $8-10$ ). These data suggest that GSTF binds to the IUF-1 binding site.

Since GSTF appeared to bind the CT2 motif, the nuclear extracts from the various HIT cell passages were tested for binding to an oligodeoxynucleotide containing the sequences -94 / -65 of the human insulin gene. This oligodeoxynucleotide probe contains the CT1 motif (CTAATG), located at -82 / -77 of the human insulin promoter, which has been shown to be an additional binding site for IUF-1 (25). With the -94 / -65 oligodeoxynucleotide probe, one prominent DNA-protein complex was observed with nuclear extracts from passage 74 cells (Fig. 2, lane 2). Nuclear extracts from passage $133 \mathrm{HIT}$ cells chronically cultured in $11.1 \mathrm{mM}$ glucose were unable to form this DNA-protein complex (Fig. 2, lane 3). In contrast, nuclear extracts from passage 133 HIT cells chronically cultured in $0.8 \mathrm{mM}$ glucose retained the ability to form this DNAprotein complex (Fig. 2, lane 4). The specificity of the DNAprotein complex formed with nuclear extracts from HIT cell
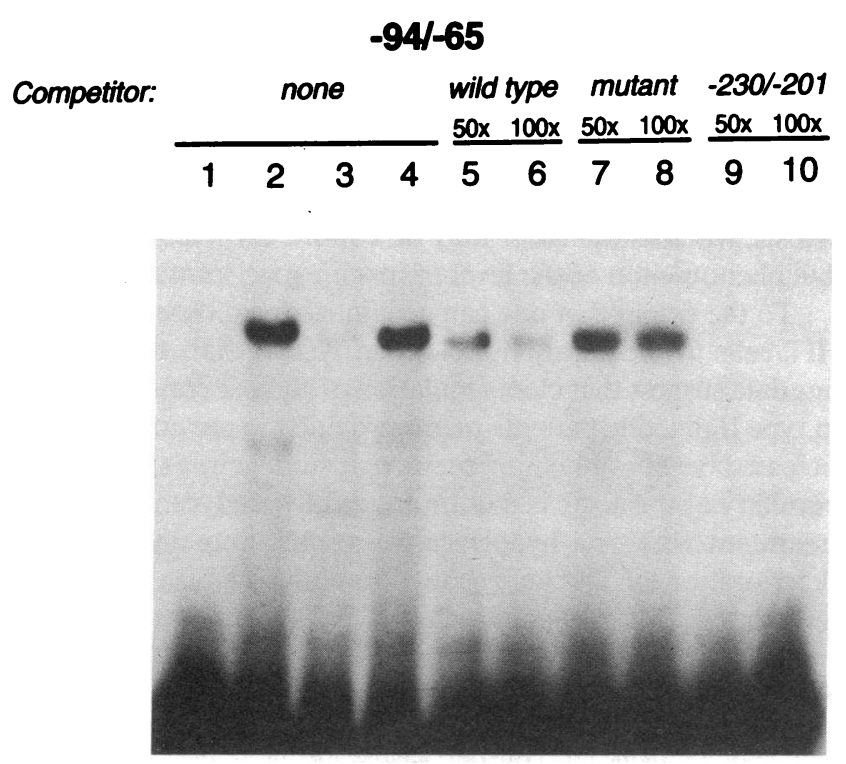

Figure 2. Analysis of protein binding to insulin promoter sequences from -94 to -65 using nuclear extracts from an early and late passage of HIT cells serially passaged in either $11.1 \mathrm{mM}$ or $0.8 \mathrm{mM}$ glucose. Lane 1, free probe; lanes 2, 5-10, nuclear extract from HIT cell passage 74; lane 3, nuclear extract from HIT cell passage 133 serially passaged in $11.1 \mathrm{mM}$ glucose; lane 4, nuclear extract from HIT cell passage 133 serially passaged in $0.8 \mathrm{mM}$ glucose. Competitor added, lanes 5-6, 50- and 100-fold excess of unlabeled wildtype -94/-65; lanes 7-8, 50- and 100-fold molar excess of unlabeled mutated -94/ -65 ; lanes 9-10, 50- and 100-fold molar excess of unlabeled -230 / -201 . passage 74 was determined by using an excess of unlabeled $-94 /-65$ deoxynucleotide probe to compete for binding (Fig. 2 , lanes 5,6 ).

The protein-DNA complex formed with the HIT cell passage 74 nuclear extract and the $-94 /-65$ oligodeoxynucleotide was directly competed by the addition of excess unlabeled $-230 /-201$ DNA (Fig. 2, lanes 9, 10). These data suggest that the transcription factor present in nuclear extracts from passage 74 HIT cells and passage 133 HIT cells cultured in $0.8 \mathrm{mM}$ glucose, but absent in passage 133 HIT cells cultured in 11.1 mM glucose, which binds to $-94 /-65$ probe, may be related to GSTF. To further investigate this possibility, the CT1 motif $(-82 /-77$, CTAATG) contained within the $-94 /-65$ oligodeoxynucleotide probe was mutated to GCGCGC and tested for its ability to compete for nuclear extract binding to the wild type $-94 /-65$ deoxynucleotide probe. This mutated oligodeoxynucleotide no longer competed for the specific DNAprotein complex present in passage 74 HIT cells (Fig. 2, lanes $7,8)$. Overall these data suggest that GSTF binds to the CT motifs, which have been previously shown to bind IUF-1.

Mutations of GSTF binding sites within 5'-regulatory domain of the human insulin gene lead to decreased expression of INSCAT reporter gene. To test whether the loss of GSTF correlates to the decreased expression of INSCAT in late passages of HIT cells serially passaged in $11.1 \mathrm{mM}$ glucose, site-directed mutations of the GSTF binding sites within the INSCAT vector were constructed and tested in the various HIT cell passages. Three mutant INSCAT vectors were constructed; mCT2CAT in which the CT2 motif was mutated to ACGCGT, mCT1CAT in which the CT1 motif was mutated to GCGCGC, and $\mathrm{mCT} 1 \mathrm{CT} 2 \mathrm{CAT}$ in which the CT1 and CT2 motifs were mutated to GCGCGC and ACGCGT, respectively. The expression of the mCT1CT2CAT vector, in which both GSTF binding sites were mutated, is markedly decreased in early passages of HIT cells and in late passages of HIT cells cultured in either $11.1 \mathrm{mM}$ or $0.8 \mathrm{mM}$ glucose (Fig. 3). Mutation of the individual GSTF binding sites (mCT1CAT or mCT2CAT) also tended to decrease CAT expression in all HIT cell passages, but these effects were not always statistically significant. These data indicate that the GSTF binding sites present within the 5'-regulatory domain of the human insulin gene play a functional role in the regulation of insulin gene transcription and that the loss of GSTF binding leads to decreased insulin gene transcription.

\section{Discussion}

In experiments designed to examine potentially adverse effects of high glucose concentrations on insulin gene transcription, we found that the activity of the insulin gene promoter is decreased in HIT cells serially passaged in maximally stimulatory concentrations of glucose. This can be partially prevented by culturing HIT cells in a lower glucose concentration. The changes in the activity of the insulin promoter correlate with changes in insulin mRNA levels for the different HIT cell passages (11). The observation that chronic exposure of HIT cells to high glucose concentration leads to decreased insulin gene expression represents an apparent time-related paradox. Acute increases in glucose concentrations have been shown to increase insulin mRNA levels (26-30) by both stabilizing insulin message (30) and increasing the rate at which the insulin gene 


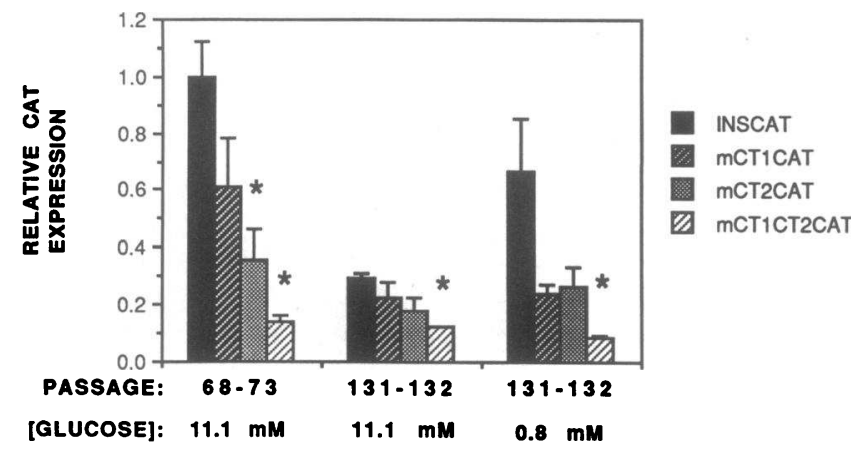

Figure 3. Functional analysis of the CT motifs contained within the human insulin gene promoter. Early and late passages of HIT cells serially passaged in $11.1 \mathrm{mM}$ and $0.8 \mathrm{mM}$ glucose were transiently transfected with INSCAT vectors with either the CT1 (mCT1CAT), CT2 (mCT2CAT), or both the CT1 and CT2 (mCT1CT2CAT) motifs mutated. The sequence CTAATG was mutated to GCGCGC and ACGCGT for the CT1 and CT2 motifs, respectively. The relative expression of the INSCAT to RSVCAT are normalized to expression observed in early passages of HIT cells. Data represent the mean \pm SEM for 3 independent experiments with duplicate observations $(n=3) .{ }^{*} P<0.05$, significance of relative CAT expression between the wildtype INSCAT and mutant INSCAT vectors for each individual passage.

is transcribed $(26,31,32)$. The chronic effect of glucose on insulin gene transcription that we describe and which can be partially prevented by chronically culturing HIT cells in lower glucose concentrations, may represent a direct glucose toxic effect on a insulin-gene specific transcription factor(s).

A glucose-responsive DNA element has been mapped to $-247 /-196$ of the rat 1 insulin gene enhancer (31). Both ubiquitous transcription factors, Pan- 1 and Pan-2 (33-36), and $\beta$ cell specific factors (37-39) have been shown to bind to DNA sequences contained in this glucose-responsive region. $\mathrm{A} \beta$ cell specific factor (IUF-1) binds to the CT motifs (CTAATG) located at $-215 /-210$ (CT2 motif) and $-82 /-77$ (CT1 motif) in the human insulin gene enhancer (25). The CT motifs are highly conserved across all mammalian species, suggesting that these motifs may participate in the transcriptional regulation of the insulin gene. The CT2 motif of the human insulin gene is similar to sequences located in the FLAT element $(-222 /$ -208 ) of rat 1 insulin gene (40). Mutations of the FLAT element have been shown to decrease the rat 1 insulin gene promoter activity (41) and to alter the activity of a rat 1 insulin gene mini-enhancer linked to a heterologous promoter (40). Recently, German et al. has cloned two protein factors, $\operatorname{lmx}-1$ and cdx-3, which bind to the FLAT element (42). Lmx-1, a $\beta$ cell specific LIM-homeo domain protein, synergistically interacts with Pan-1 and increases the expression of the rat 1 insulin gene mini-enhancer in nonpancreatic beta cells (42). However, the relationship between IUF-1 and FLAT element binding proteins, $\operatorname{lm} x-1$ and $c d x-3$, has yet to be determined.

Our data show that nuclear extracts made from late passages of HIT cells chronically cultured in a high glucose concentration fail to form a specific DNA-protein complex (GSTF) to sequences $-230 /-201$ and $-94 /-65$ of the human insulin gene and that GSTF requires the CT motifs contained within these sequences for binding. Our studies also demonstrate that mutations of the CT motifs decrease insulin pro- moter activity in all passages of HIT cells. These data suggest that the CT motifs play a functional role in the regulation of the human insulin gene promoter activity. Our findings strongly suggest that the mechanism of action for the decrease in insulin gene transcription in cells cultured chronically in high glucose concentrations is the loss of GSTF binding to the CT motifs either because GSTF has been altered or is no longer present. The exact relationship between IUF-1 and GSTF has not been resolved, but they may be closely related to the FLAT binding proteins, $\operatorname{lm} x-1$ or $c d x-3$. The decrease in insulin gene transcription is not due to the loss of a transcription factor that binds to the strong enhancer element located between -249 and -220 of the human insulin gene because similar levels of DNA-protein complexes, assessed by EMSA, were formed when using nuclear extracts from HIT cells chronically cultured in high or low glucose concentrations.

The loss of insulin response to glucose in HIT cells serially passaged in high glucose concentrations and the ability to prevent this by passaging cells in a more physiological glucose concentration is reminiscent of the adverse effects of chronic hyperglycemia which occur in patients with type II diabetes mellitus and animal models fed excess glucose. Although it is generally thought that such glucose toxic effects occur at sites within the exocytotic pathway, our results suggest that these adverse effects occur at the level of the insulin gene and lead to a paradoxical decrease in the rate of transcription. Recently published data demonstrated that prolonged exposure of the human pancreatic islet to high glucose concentrations leads to impaired insulin secretion (43). This was attributed mainly to a decline in insulin content that was preventable by culturing the islets in low glucose concentrations (43). This conclusion is consistent with our suggestion that $\beta$ cells are sensitive to direct glucose toxic effects on insulin gene transcription. We therefore propose a time-related distinction between the terms $g l u$ cose desensitization and glucose toxicity. The former may be a more acute, reversible phenomenon at the level of insulin exocytosis, whereas the latter may be a more chronic, less reversible phenomenon at the level of insulin gene transcription.

To the extent that one can generalize from observations in HIT cells to the pathophysiology in type II diabetic patients, our data suggest that close regulation of glucose concentrations in type II diabetic patients might provide the previously unanticipated benefit of helping preserve insulin gene expression. A corollary of this logic is that prolonged hyperglycemia, despite treatment with oral hypoglycemic agents, may contribute to deterioration of insulin production and secretion and, thus, lead to so-called "secondary failure" of these drugs.

\section{Acknowledgments}

The authors thank Dr. Hui-Jian Zhang for the initial culturing and characterization of the HIT cell passages and express their gratitude to Mersini Spiropoulos for secretarial help.

This work was supported by National Institutes of Health grants RO1-DK-38325 (R. P. Robertson), RO1-DK-26919 (H. C. Towle), and F32-DK-08742 (L. K. Olson), and by the Minnesota Affiliate of the American Diabetes Association.

\section{References}

1. Unger, R. H., and S. Grundy. 1985. Hyperglycaemia as an inducer as well as a consequence of impaired islet cell function and insulin resistance: implications for the management of diabetes. Diabetologia. 28:119-121. 
2. Robertson, R. P. 1989. Type II diabetes, glucose "non-sense," and islet desensitization. Diabetes. 38:1501-1505.

3. Turner, R. C., S. T. McCarthy, R. R. Holman, and E. Harris. 1976. Betacell function improved by supplementing basal insulin secretion in mild diabetes. Brit. Med. J. 1:1252-1254.

4. Schmeltz, R., H. J. Wendorff, and J. B. Field. 1978. Effect of control of blood glucose on plasma insulin responses to various stimuli in secondary failures to oral hypoglycemic agents and in newly diagnosed, maturity onset, ketosis-resistant diabetics. J. Clin. Endocrinol. \& Metab. 46:519-527.

5. Kosaka, K., T. Kuzuya, Y. Akanuma, and R. Hagura. 1980. Increase in insulin response after treatment of overt maturity-onset diabetes is independent of the mode of treatment. Diabetologia. 18:23-28.

6. Hidaka, H., M. Nagulesparan, I. Klimes, R. Clark, H. Sasaki, S. L. Aronoff, B. Vasquez, A. H. Rubenstein, and R. H. Unger. 1982. Improvement of insulin secretion but not insulin resistance after short term control of plasma glucose in obese Type II diabetics. J. Clin. Endocrinol. \& Metab. 54:217-222.

7. Vague, P., and J.-P. Moulin. 1982. The defective glucose sensitivity of the $\beta$ cell in non-insulin dependent diabetes. Improvement after twenty hours of normoglycaemia. Metab. Clin. Exp. 31:139-142.

8. Rossetti, L., G. I. Shulman, W. Zawalich, and R. A. DeFronzo. 1987. Effect of chronic hyperglycemia on in vivo insulin secretion in partially pancreatectomized rats. J. Clin. Invest. 80:1037-1044.

9. Imamura, T., M. Koffler, J. H. Helderman, D. Prince, R. Thirlby, L. Inman, and R. H. Unger. 1988. Severe diabetes induced in subtotally depancreatized dogs by sustained hyperglycemia. Diabetes. 37:600-609.

10. Leahy, J. L., S. Bonner-Weir, and G. C. Weir. 1988. Minimal chronic hyperglycemia is a critical determinant of impaired insulin secretion after an imcomplete pancreatectomy. J. Clin. Invest. 81:1407-1414.

11. Robertson, R. P., H.-J. Zhang, K. L. Pyzdrowski, and T. F. Walseth. 1992. Preservation of insulin mRNA levels and insulin secretion in HIT cells by avoidance of chronic exposure to high glucose concentrations. J. Clin. Invest. 90:320325 .

12. Santerre, R. F., R. A. Cook, R. M. D. Crisel, J. D. Sharp, R. J. Schmidt, D. C. Williams, and C. P. Wilson. 1981. Insulin synthesis in a clonal cell line of simian virus 40-transformed hamster pancreatic beta cells. Proc. Natl. Acad. Sci. USA. 78:4339-4343.

13. Hill, R. S., and A. E. Boyd, III. 1985. Perifusion of a clonal cell line of simian virus 40-transformed beta cell. Insulin secretory dynamics in response to glucose, 3-isobutyl-1-methylxanthine, and potassium. Diabetes. 34:115-120.

14. Ashcroft, S. J. H., P. Hammonds, and D. E. Harrison. 1986. Insulin secretory responses of a clonal cell line of simian virus 40 -transformed $\beta$ cells. Diabetologia. 29:727-733.

15. Lambert, D. G., K. Hughes, and T. W. Atkins. 1986. Insulin release from a cloned hamster $\beta$-cell line (HIT-T15). The effects of glucose, amino acids, sulphonylureas and colchicine. Biochem. Biophys. Res. Commun. 140:616-625.

16. Meglasson, M. D., C. D. Manning, H. Najafi, and F. M. Matschinsky. 1987. Fuel-stimulated insulin secretion by clonal hamster $\beta$-cell line HIT T-15. Diabetes. 36:477-484.

17. Robertson, R. P., P. Tsai, S. A. Little, H.-J. Zhang, and T. F. Walseth 1987. Receptor-mediated adenylate cyclase-coupled mechanism for $\mathrm{PGE}_{2}$ inhibition of insulin secretion in HIT cells. Diabetes. 36:1047-1053.

18. Zhang, H.-J., T. F. Walseth, and R. P. Robertson. 1989. Insulin secretion and cAMP metabolism in HIT cells. Reciprocal and serial passage-dependent relationships. Diabetes. 38:44-48.

19. Jacoby, D. B., N. D. Zilz, and H. C. Towle. 1989. Sequences within the 5 '-flanking region of the $S_{14}$ gene confer responsiveness to glucose in primary hepatocytes. J. Biol. Chem. 264:17623-17626.

20. Kingston, R. E., and J. Sheen. 1991. Introduction of DNA into mammalian cells. In Current Protocols in Molecular Biology. F. Ausubel, R. Brent, R. Kingston, D. Moore, J. Seidman, J. Smith, and K. Struhl, editors. Greene Publishing Associates and Wiley-Interscience, New York. 9.0.1-9.9.6

21. Dignam, J. D., R. M. Lebovitz, and R. G. Roeder. 1983. Accurate transcription initiation by RNA polymerase II in a soluble extract from isolated mammalian nuclei. Nucleic Acids Res. 11:1475-1489.

22. Abmayr, S. M., and J. L. Workman. 1991. DNA-protein interactions. In
Current Protocols in Molecular Biology. F. Ausubel, R. Brent, R. Kingston, D. Moore, J. Seidman, J. Smith, and K. Struhl, editors. Greene Publishing Associates and Wiley-Interscience, New York. Supplement: 12.0.1-12.1.9

23. Shih, H.-M., and H. C. Towle. 1992. Definition of the carbohydrate response element of the rat $\mathrm{S}_{14}$ gene. Evidence for a common factor required for carbohydrate regulation of hepatic genes. J. Biol. Chem. 267:13222-13228.

24. Boam, D. S. W., A. R. Clark, and K. Docherty. 1990. Positive and negative regulation of the human insulin gene by multiple trans-acting factors. J. Biol. Chem. 265:8285-8296.

25. Boam, D. S. W., and K. Docherty. 1989. A tissue-specific nuclear factor binds to multiple sites in the human insulin-gene enhancer. Biochem. J. 264:233239.

26. Hammonds, P., P. N. Schofield, and S. J. H. Ashcroft. 1987. Glucose regulates preproinsulin messenger RNA levels in a clonal cell line of simian virus 40-transformed $\beta$ cells. FEBS (Fed. Eur. Biochem. Soc.) Lett. 213:149-154.

27. Giddings, S. J., J. Chirgwin, and M. A. Permutt. 1982. Effects of glucose on proinsulin messenger RNA in rats in vivo. Diabetes. 31:624-629.

28. Brunstedt, J., and S. J. Chan. 1982. Direct effect of glucose on the preproinsulin mRNA level in isolated pancreatic islets. Biochem. Biophys. Res. Commun. 106:1383-1389.

29. Hammonds, P., P. N. Schofield, S. J. H. Ashcroft, R. Sutton, and D. W. R. Gray. 1987. Regulation and specificity of glucose-stimulated insulin gene expression in human islets of Langerhans. FEBS (Fed. Eur. Biochem. Soc.) Lett. 223:131-137.

30. Welsh, M., D. A. Nielsen, A. J. MacKrell, and D. F. Steiner. 1985. Control of insulin gene expression in pancreatic $\beta$-cells and in an insulin-producing cell line, RIN-5F cells. J. Biol. Chem. 260:13590-13594.

31. German, M. S., L. G. Moss, and W. J. Rutter. 1990. Regulation of insulin gene expression by glucose and calcium in transfected primary islet cultures. $J$. Biol. Chem. 265:22063-22066.

32. Efrat, S., M. Surana, and N. Fleischer. 1991. Glucose induces insulin gene transcription in a murine pancreatic $\beta$-cell line. J. Biol. Chem. 266:11141-11143.

33. German, M. S., M. A. Blanar, C. Nelson, L. G. Moss, and W. J. Rutter. 1991. Two related helix-loop-helix proteins participate in separate cell-specific complexes that bind the insulin enhancer. Mol. Endocrinol. 5:292-299.

34. Nelson, C., L. P. Shen, A. Meister, E. Fodor, and W. J. Rutter. 1990. Pan: a transcriptional regulator that binds chymotrypsin, insulin, and AP-4 enhancer motifs. Genes \& Dev. 4:1035-1043.

35. Shibasaki, Y., H. Sakura, F. Takaku, and M. Kasuga. 1990. Insulin enhancer binding protein has helix-loop-helix structure. Biochem. Biophys. Res. Commun. 170:314-321.

36. Walker, M. D., C. W. Park, A. Rosen, and A. Aronheim. A cDNA from a mouse pancreatic $\beta$ cell encoding a putative transcription factor of the insulin gene. Nucleic Acids Res. 18:1159-1166.

37. Ohlsson, H., and T. Edlund. 1986. Sequence-specific interactions of nuclear factors with the insulin gene enhancer. Cell. 45:35-44.

38. Moss, L. G., J. B. Moss, and W. J. Rutter. 1988. Systematic binding analysis of the insulin gene transcriptional control region: Insulin and immunoglobulin enhancers utilize similar transactivators. Mol. Cell Biol. 8:2620-2627.

39. Ohlsson, H., O. Karlsson, and T. Edlund. 1988. Beta cell specific protein binds to two major regulatory sequences of the insulin gene enhancer. Proc. Natl. Acad. Sci. USA. 85:4228-4231.

40. German, M. S., L. G. Moss, J. Wang, and W. J. Rutter. 1992. The insulin and amyloid polypeptide genes contain similar cell-specific promoter element that bind identical $\beta$-cell nuclear complexes. Mol. Cell. Biol. 12:1777-1788.

41. Karlsson, O., M. D. Walker, W. J. Rutter, and T. Edlund. 1989. Individual protein-binding domains of the insulin gene enhancer positively activate $\beta$-cellspecific transcription. Mol. Cell. Biol. 9:823-827.

42. German, M. S., J. Wang, R. B. Chadwick, and W. J. Rutter. 1992. Synergistic activation of the insulin gene by a LIM-homeo domain protein and a basic helix-loop-helix protein: building a functional insulin minienhancer complex. Genes \& Dev. 6:2165-2176.

43. Eizirik, D. L., G. S. Korbutt, and C. Hellerström. 1992. Prolonged exposure of human pancreatic islets to high glucose concentrations in vitro impairs the $\beta$-cell function. J. Clin. Invest. 90:1263-1268. 